\title{
EXPLICIT BOUNDS OF UNKNOWN FUNCTION OF SOME NEW WEAKLY SINGULAR RETARDED INTEGRAL INEQUALITIES WITH APPLICATIONS
}

\author{
RICAI LUO, WU-SHENG WANG AND ZONGYI HOU
}

\begin{abstract}
Some new retarded weakly singular integral inequalities of Gronwall-Bellman type are established, which generalized some known weakly singular inequalities and can be used in the analysis of various problems in the theory of certain classes of singular differential equations, singular integral equations and singular evolution equations. Using the modification of Medved's method, the explicit estimations of unknown function in the inequalities are obtained. Finally, we give a examples to illustrate applications of our results.
\end{abstract}

Mathematics subject classification (2010): 26D10, 26D15, 26D20, 45A99. equation.

Keywords and phrases: Integral inequality, delay, weakly singular, explicit bounds, singular integral

\section{REFERENCES}

[1] T. H. GRONWALL, Note on the derivatives with respect to a parameter of the solutions of a system of differential equations, Ann Math. 20 (1919) 292-296.

[2] R. Bellman, The stability of solutions of linear differential equations, Duke Math. J. 10 (1943) 643-647.

[3] A. AbDeldaim, Nonlinear retarded integral inequalities of type and applications, J. Math. Inequal. 10 (1) (2016) 285-299.

[4] V. Lakshmikantham and S. Leela, Differential and Integral Inequalities, Theory and Applications, Academic Press, New York, 1969.

[5] D. D. Bainov And P. Simeonov, Integral Inequalities and Applications, Kluwer Academic Publishers, Dordrecht, 1992.

[6] R. P. Agarwal, Difference Equations and Inequalities, Marcel Dekker, New York, 1993.

[7] B. G. Pachpatte, Inequalities for Differential and Integral Equations, Academic Press, New York, 1998.

[8] O. Lipovan, A retarded Gronwall-like inequality and its applications, J. Math. Anal. Appl. 252 (2000) $389-401$.

[9] R. P. Agarwal, S. Deng And W. Zhang, Generalization of a retarded Gronwall-like inequality and its applications, Appl. Math. Comput. 165 (2005) 599-612.

[10] W. S. CHEUNG, Some new nonlinear inequalities and applications to boundary value problems, Nonlinear Anal. 64 (2006) 2112-2128.

[11] A. Abdeldaim And M. Yakout, On some new integral inequalities of Gronwall-BellmanPachpatte type, Appl. Math. Comput. 217 (2011) 7887-7899.

[12] H. El-Owaidy, A. A. Ragab, W. Abuelela, A. A. El-Deeb, On some new nonlinear integral inequalities of Gronwall-Bellman type, KYUNGPOOK Math. J. 54 (2014) 555-575.

[13] D. Henry, Geometric Theory of Semilinear Parabolic Equations, Lecture Notes in Math., vol. 840, Springer-Verlag, New York/Berlin, 1981.

[14] H. Sano AND N. Kunimatsu, Modified Gronwall's inequality and its application to stabilization problem for semilinear parabolic systems, Systems Control Lett. 22 (1994) 145-156. 
[15] H. P. YE, J. M. GAO, Y. S. DiNG, A generalized Gronwall inequality and its application to a fractional differential equation, J. Math. Anal. Appl. 328 (2007) 1075-1081.

[16] M. MEDVEĎ, A new approach to an analysis of Henry type integral inequalities and their Bihari type versions, J. Math. Anal. Appl. 214 (1997) 349-366.

[17] M. Medveš, Integral inequalities and global solutions of semilinear evolution equations, J. Math. Anal. Appl. 267 (2002) 643-650.

[18] Q. H. MA AND J. PEČARIĆ, Some new explicit bounds for weakly singular integral inequalities with applications to fractional differential and integral equations, J. Math. Anal. Appl. 341 (2) (2008) 894-905.

[19] M. MEDVĚ̌, Nonlinear singular integral inequalities for functions in two and $n$ independent variables, J. Inequal. Appl. 5 (2000) 287-308.

[20] Q. H. MA AND E. H. YANG, Estimations on solutions of some weakly singular Volterra integral inequalities, Acta Math. Appl. Sin. 25 (2002) 505-515.

[21] S. Deng, C. Prather, Generalization of an impulsive nonlinear singular Gronwall-Bihari inequality with delay, J. Inequal. Pure Appl. Math. 9 (2008) Article 34.

[22] S. MAZOUZI AND N. TATAR, New bounds for solutions of a singular integro-differential inequality, Math. Inequal. Appl. 13 (2) (2010) 427-435.

[23] H. WANg AND K. Zheng, Some nonlinear weakly singular integral inequalities with two variables and applications, J. Inequal. Appl. 2010 (2010) Article ID 345701.

[24] K. Cheng, C. Guo AND M. TANG, Some nonlinear Gronwall-Bellman-Gamidov integral inequalities and their weakly singular analogues with applications, Abstr. Appl. Anal. 2014 (2014) Article ID 562691.

[25] B. ZHENG, Explicit bounds derived by some new inequalities and applications in fractional integral equations, J. Inequal. Appl. 2014 (2014) Article 4.

[26] Y. OUYANG AND W. S. WANG, A class of weakly singular nonlinear Volterra-Fredholm type iterated integral inequality with $p$ th power and its application, Journal of Sichuan Normal University (Natural Science) 39 (2016) 209-213.

[27] C. M. HUANG AND W. S. WANG, Weakly singular nonlinear iterated integral inequality with its applications, Journal of Sichuan Normal University (Natural Science) 39 (2016), 214-220.

[28] R. Xu AND F. Meng, Some new weakly singular integral inequalities and their applications to fractional differential equations, J. Inequal. Appl. 2016 (2016) Article 78.

[29] M. KuCZMA, An introduction to the theory of functional equations and inequalities: Cauchy's equation and Jensen's inequality, University of Katowice, Katowice, 1985.

[30] F. C. JiAng AND F. W. Meng, Explicit bounds on some new nonlinear integral inequalities with delay, J. Comput. Appl. Math. 205 (2007) 479-486.

[31] D. Willett, Nonlinear vector integral equations as contraction mappings, Arch. Ration. Mech. Anal. 15 (1964) 79-86.

[32] D. S. Mitrinović, Analytic Inequalities, Springer-Verlag, Berlin, 1970. 